\title{
PROGRESSIVE COLLAPSE ANALYSIS OF THE LOCAL ELEMENTS AND ULTIMATE STRENGTH OF A RO-RO SHIP
}

\author{
Muhammad Zubair Muis Alie ${ }^{1 *}$, Samuel Izaak Latumahina ${ }^{1}$ \\ ${ }^{1}$ Department of Ocean Engineering, Engineering Faculty, Hasanuddin University, Gowa 92171, \\ Indonesia
}

(Received: March 2018 / Revised: November 2018 / Accepted: May 2019)

\begin{abstract}
One of the most important criteria in ship design is strength. When a ship is under external loads such as waves, buoyancy or pressure, its internal reaction must resists those external loads. In this regard, external loads are retained by the hull girder, whose cross section is composed of plates and stiffeners, which have a significant influence on ultimate strength, especially in the longitudinal direction. Therefore, this strength must be assessed and evaluated for the ship structure and functional requirements. In this study, local elements of the ship cross section, such as plates and stiffeners, are analyzed, including their progressive collapse behavior. The example used for the calculation is a Roll-on/Roll-off (Ro-Ro) ship. The analysis is performed by assuming that the cross section remains plane and a one-frame space is considered. To calculate the ultimate strength of the Ro-Ro ship under hogging and sagging conditions, Smith's method is used and applied to an in-house program. The applied moment is given on the Multi Point Constraint (MPC) as the reference point of the neutral axis position. In this MPC position, a simple support is attached. The calculation of ultimate strength is made under hogging and sagging conditions, and the intact condition is focused on for the simple calculation. Welding residual stress, cracks, corrosion and initial deflection are not taken into account. Application of the FE method is also made to investigate the characteristics of the collapse mode for local elements and global structure, including ultimate strength.
\end{abstract}

Keywords: Cross section; Hull girder; Intact condition; Local elements; Ro-Ro ship; Ultimate strength

\section{INTRODUCTION}

It is well known that ultimate strength is vital in ship design. This strength must be assessed to protect ships from damage. In this study, three types of strength will be assessed: longitudinal, transversal and local. Longitudinal strength is the most significant of these, and the parameter which is always assessed to establish the bending moment capacity of a ship against external loads when at sea.

Previous studies have discussed the ultimate strength of ship structures. Tekgoz et al. (2018) analyzed a container ship under asymmetrical bending conditions, taking into account the influence of structural damage, the associated neutral axis translation, and the rotation of the residual load carrying capacity. FE analysis and a formulation based on the Common Structural Rules (CSR) were employed. The ship was analyzed in intact and damaged conditions. An asymmetrically damaged ship under a sagging condition was investigated by Muis-Alie (2018)

*Corresponding author's email: zubair.m@eng.unhas.ac.id, Tel. 081382815767

Permalink/DOI: https://doi.org/10.14716/ijtech.v10i5.1768 
A plate and/or stiffened plate element in the so-called "critical element" specified location reached its ultimate strength, demonstrating that the hull girder had also attained ultimate strength. Nugroho et al. (2018) elaborated a conventional tee stiffener profile on the midship section of an oil tanker structure. Ultimate strength analysis was conducted using the finite element method for all the stiffeners with various geometrical dimensions, according to the International Association of Classification Societies. Kim and Paik (2017) expanded a fully automated method to optimize design for the hull structural scantling of merchant cargo ships, with a plate-shell used for modeling. To minimize the structural weight and maximize structural safety, a technique for full optimization with multi-objectives was employed, based on the design constraint related to the ultimate limit states of the plate panels, support members and hull girders. The development procedure was implemented on a Very Large Crude Carrier (VLCC) hull structure, the procedure's capacity is shown by this test for requirement of common structural rules. An assessment of the ultimate strength of a Ro-Ro ship after damage was conducted by Muis Alie et al. (2017), with the calculation focused on the cross section. The side shell of the hull and bottom part were assumed to be damaged by simply removing those elements on the bottom part. The results of the analytical solution were compared for intact and damaged statuses under hogging and sagging conditions. Reliability analysis of an oil tanker in an intact condition was conducted by Campanile et al. (2017) to investigate the incidence of load combination methods on hull girder sagging/hogging time-variant failure probability. Using Monte Carlo simulation, the statistical properties of time-variant ultimate strength were determined up to a 25-year ship lifetime. To determine the bending capacity, a modified incremental-iterative method was used, taking into account the corrosion wastage of the structural members influencing hull girder strength, welding residual stresses, and material properties randomness. Gaspar et al. (2016) evaluated the influence of nonlinear vertical waveinduced bending moments on ship hull girder reliability. A chemical tanker, for which the nonlinearity of the vertical wave-induced bending moments was found to be significant, was used as a case study. Muis Alie et al. (2016) used the finite element method to analyze the ultimate strength of asymmetrically damaged ships. The collision damage was simply created and removes the elements. A comparison between the FE analysis and analytical solution was made, including the collapse behavior of the ship's hull. The ultimate strength of Floating Production Storage Offloading (FPSO) was calculated by Chen (2016) using reliability assessment methodology. Application of Smith's method was made to calculate the hull girder ultimate strength of an FPSO. Ultimate strength analysis, including buckling and fatigue, was conducted by Muis Alie (2016) on a fixed jacket platform. The finite element method was employed to analyze the structure, and the symmetrical and asymmetrical shape was taken as the object of the analysis. Ultimate limit state-based ultimate longitudinal strength analysis was performed by Park et al. (2015) to identify the operability of aged non-ice class ships in the Arctic Ocean with consideration of aging. Hull girder ultimate strength was verified by Garbatov et al. (2015) based on the class society and the results obtained by experimental and dimensional theory. Kukkanen and Matusiak (2014) presented a nonlinear time domain calculation method, taking the model test of a roll-on/roll-off passenger ship with a flat bottom stern into account. Using the calculation method and model test results, the nonlinearities in ship motion and hull girder loads were investigated. Residual strength analysis of a ship with bottom damage was conducted by Muis Alie (2014) taking the full cross section into consideration and using the nonlinear finite element method. Improved assessment of ultimate bending capacity was proposed by Kitarovic and Zanic (2014) to enhance the ultimate limit state evaluation in the concept design of monotonous thin-walled structures, predominantly subjected to vertical bending loads during their exploration. The hull girder moment capacity of a Very Large Crude Carrier (VLCC), called energy concentration (EC), for which many benchmark studies have been conducted using the simple progressive collapse method (SPCM), 
was predicted by Tayyar et al. (2014). The structural strength of the MV Nakhodka was investigated by Yao et al. (1998); applying the NK Rule, longitudinal strength was examined and evaluated using a simplified method of progressive collapse analysis.

In this study, the local elements of the ship cross section and ultimate strength are analyzed, including their progressive collapse behavior. The example for the calculation is a Roll-on/Rolloff (Ro-Ro) ship and only one frame space is employed. An in-house program and finite element analysis are used to calculate the ultimate strength of the Ro-Ro ship. The applied moments are given on both sides of the cross section, together with the boundary conditions, which are assumed to be simply supported. Ultimate strength is analyzed by considering hogging and sagging under longitudinal bending only for an intact condition. For the simple calculation, other parameters such as welding residual stress, cracks, corrosion, and initial imperfections are not taken into account. The finite element method is also employed to investigate the collapse modes for local elements and the global ship structure.

\section{THEORETICAL APPROACH}

The ship cross section is subdivided into stiffened and unstiffened plates; the individual elements are shown together with their coordinates and dimensions in Figure 1 . The $\mathrm{y}_{\mathrm{i}}$ and $\mathrm{z}_{\mathrm{i}}$ are the coordinates of the local elements measured from their origin at the keel.

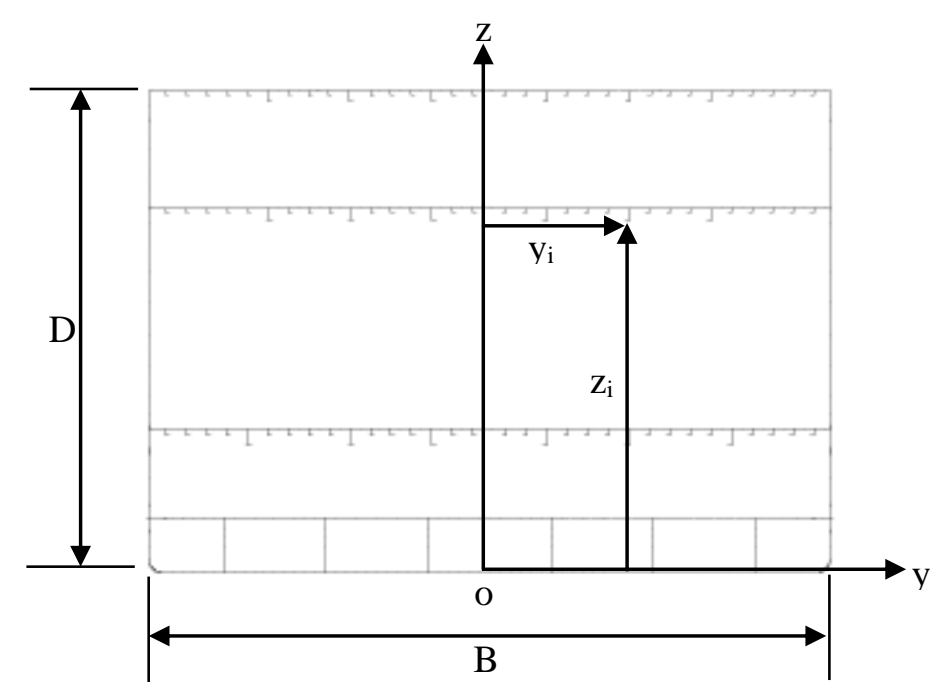

Figure 1 Cross section with individual element

In Figure 1, B and D are the breadth and depth of the ship respectively, and $y_{i}$ and $z_{i}$ are the reference coordinates of the individual element. The section property calculation of the individual elements is made in general way. The neutral axis, $\mathrm{g}$, of the hull cross section can be obtained by assuming that all the longitudinal strength elements are fully effective, as follows:

$$
g=\frac{\sum A_{i} z_{i}}{\sum A_{i}}
$$

where $A_{i}$ is the cross-sectional area of the individual element with fully effective attached plating, and $z_{i}$ is the coordinate of the individual element measured from the base line to the deck, where $z=0$ and is taken from the base line. The moment of inertia, $I_{y}$, of the hull cross section is calculated by the following formula:

$$
I_{y}=\sum A_{i}\left(z_{i}-g\right)^{2}+\sum i_{y i}
$$


where $i_{y i}$ is the local moment of inertia for each individual element corresponding to its own neutral axis. The section moduli at the deck and bottom part are determined by the equations below:

$$
\begin{aligned}
Z_{D} & =\frac{I_{y}}{D-g} \\
Z_{B} & =\frac{I_{y}}{g}
\end{aligned}
$$

The axial stress $\sigma_{i}$, corresponding to the axial strain ${ }_{\varepsilon_{i}}$ for the calculation of individual elements, is given by the stress-strain relationship, as illustrated in Figure 2.

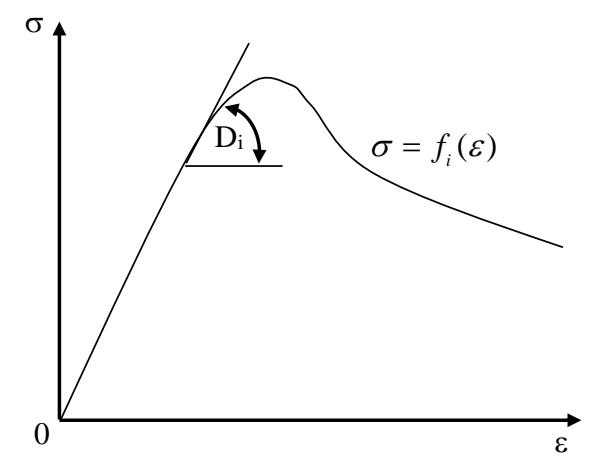

Figure 2 Stress-strain relationship of an individual element

By considering buckling and yielding, which are generally a nonlinear function of strain, the stress-strain relationship may be expressed as:

$$
\sigma=f_{i}(\varepsilon)
$$

It should be noted that under pure vertical bending, the following condition must be fulfilled and there is no axial force acting along the neutral axes, so that:

$$
\int \sigma_{x} d A=0
$$

Since $f_{i}(0)=0$, then by integrating axial stress over the intact part of the cross section, the axial force $P$, the vertical bending moment $M_{V}$, and the horizontal bending moment $M_{H}$ can be obtained as:

$$
\begin{gathered}
P=\sum_{i=1}^{N} \sigma_{i} A_{i}=0 \\
M_{V}=\sum_{i=1}^{N} \sigma_{i} y_{i} A_{i} \\
M_{H}=\sum_{i=1}^{N} \sigma_{i} z_{i} A_{i}
\end{gathered}
$$

where $N$ and $A_{i}$ are the number of intact elements and the cross-sectional area of the individual elements.

\section{METHOD OF ANALYSIS}

Analysis of the local elements and their progressive collapse was made using an in-house program adopting Smith's method and the finite element method. The cross section of a Ro-Ro ship comprises three decks, the car, passenger and top decks. The cross section modelled 
consisted of stiffened and and unstiffened plates. The properties of the individual elements were calculated in advance by considering the effect of buckling and yielding in order to obtain the stress-strain relationship. The length, breadth and depth of the ship were $68000 \mathrm{~mm}, 15000 \mathrm{~mm}$ and $10693 \mathrm{~mm}$, respectively. The ship's length was represented by a one-frame space with length is $550 \mathrm{~mm}$. The cross section was assumed to be plane and simple supports were placed on both sides of the cross section, as shown in Figure 3. The analysis of the local elements and the ultimate strength, including their progressive collapse, was made by taking an intact condition into account under longitudinal bending in hogging and sagging.

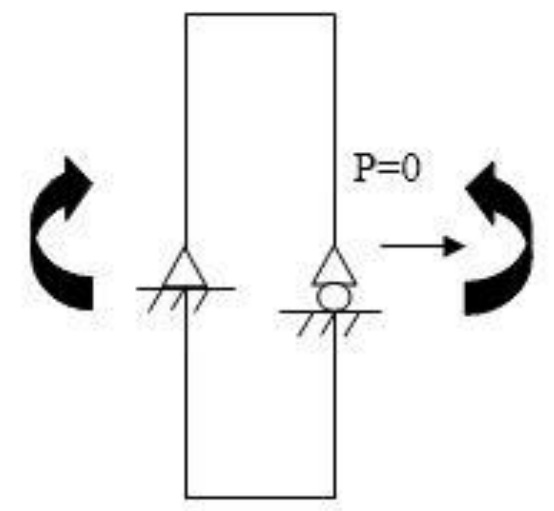

Figure 3 Boundary condition

For comparison purposes, the in-house program was compared with the finite element method. The analysis of the local elements and the ultimate strength of the Ro-Ro ship hull girder can be expressed in terms of shape deformation, stress distribution and the moment-curvature relationship.

The finite element method (FEM) was employed to evaluate the ultimate strength, including the behavior of the Ro-Ro ship under hogging and sagging. A vertical bending moment was imposed on both sides of the cross section. Multi Point Constraint (MPC) was adopted to express the behavior of the local elements when the load and/or moment acted on the cross section. The simple support and master nodes were placed on the left- and right-hand sides of the cross section where the MPC was located. The shell element was adopted to model the elements. The material was assumed to be homogenous and isotropic. For the simple analysis, the strain-hardening, initial imperfection, welding residual stress, and damage such as that from collisions, grounding and cracks were not included in the analysis. The finite element model generated in the study is illustrated in Figure 4, including its boundary conditions, meshing, multi point constraint and master nodes on both sides of the cross section. The ultimate strength obtained by FE analysis was compared to the analytical solution performed by HULLST. The general procedure of Smith's method is summarized as follows: (1) the program was developed by adopting Smith's method where the cross section of the ship was divided by a simple element composed of stiffened and attached plating; (2) the average stress-strain relationship for individual elements with consideration of buckling and yielding was derived; (3) the tangential axial stiffness of individual elements using the slope of the average stress-average strain curve at the present strain was derived; (4) the position of the instantaneous neutral axis was determined; (5) the flexural stiffness of the cross-section with respect to the instantaneous neutral axis was determined; and (6) the strain increments in individual elements under the applied curvature increment, and their stress increments using the slope of the average stressaverage strain curve were calculated. 


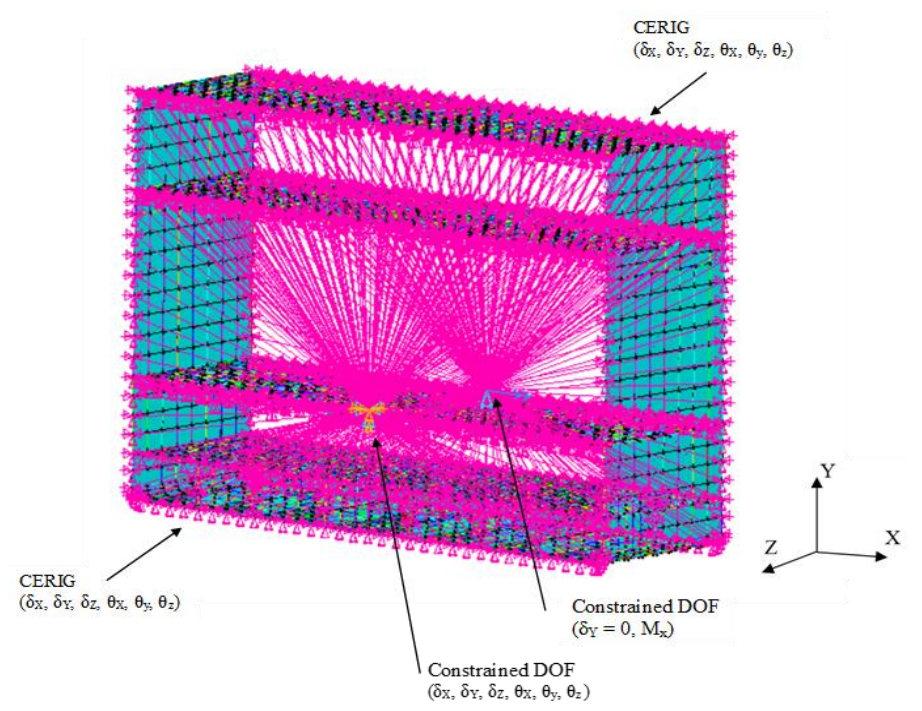

Figure 4 Boundary conditions for the FE model

\section{RESULTS AND DISCUSSION}

Analysis of the local elements and the ultimate strength of the Ro-Ro hull girder was made using the finite element method (FEM), together with the behavior of local elements such as shape deformation, stress distribution, and the moment-curvature relationship in hogging and sagging conditions. In this study, the local element responses were investigated at the bottom, and on the car, passenger and top deck. Only the intact condition was analyzed. Figures 5-8 (a) and (b) show the local deformations on the top, passenger and car decks and the bottom part in hogging and sagging conditions, respectively. In Figures $5 \mathrm{a}$ and $5 \mathrm{~b}$, it can be seen that the local elements are deformed due to tension under hogging, while the other elements on the deck part is under compression in a sagging condition.

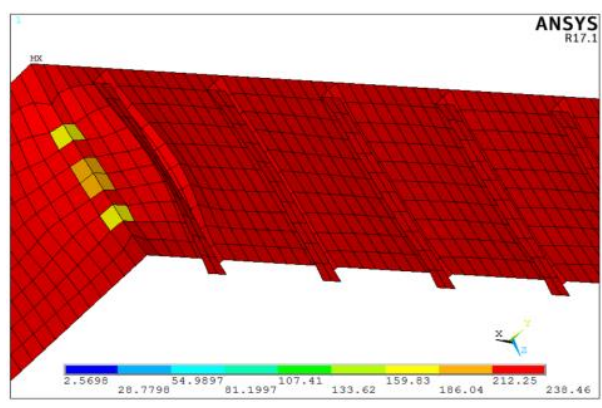

(a)

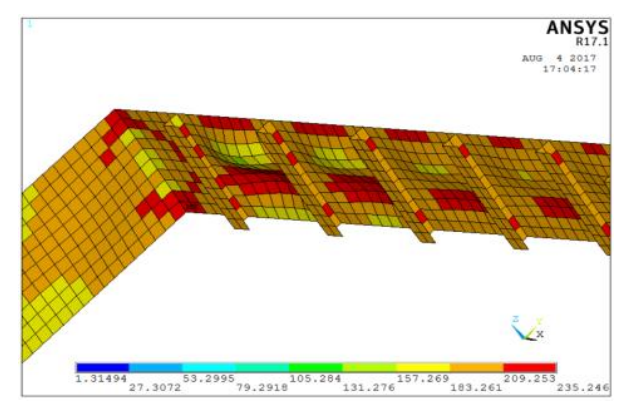

(b)

Figure 5 Local deformations at top deck: (a) hogging; and (b) sagging

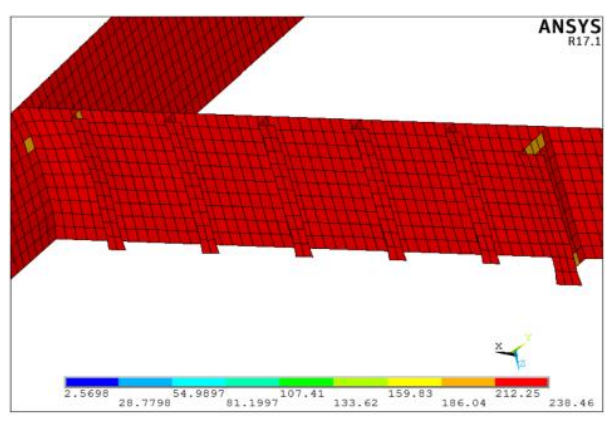

(a)

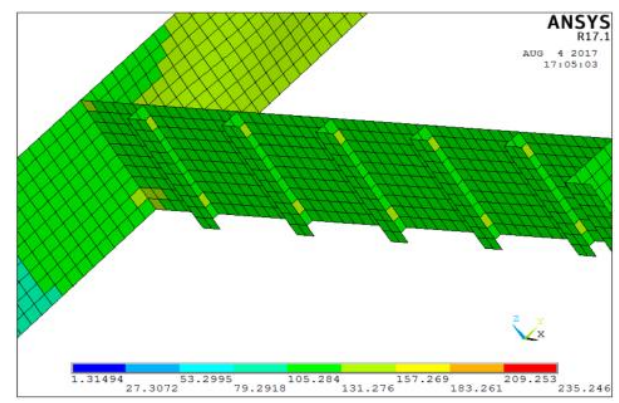

(b)

Figure 6 Local deformations on the passenger deck: (a) hogging; and (b) sagging 


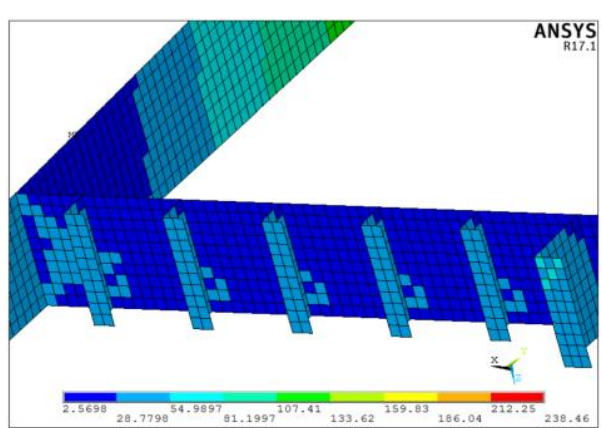

(a)

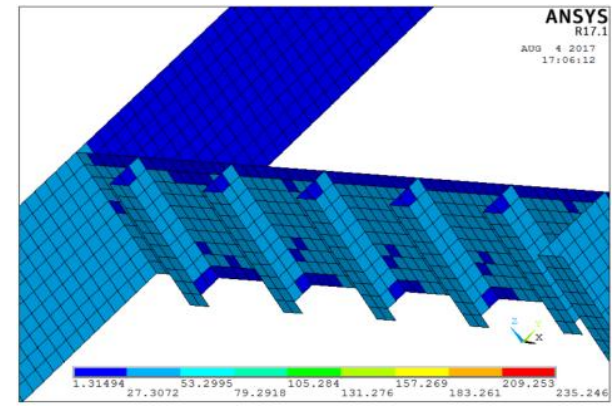

(b)

Figure 7 Local deformations on the car deck: (a) hogging; and (b) sagging

Figures 6-7 (a) and (b) show the deformations of the local elements are not significant under hogging and sagging conditions. This behavior may be realistic, because a Ro-Ro ship consists of car and passenger decks, so even the vertical bending moment applied to the cross section, and the tension and compression do not have a significant influence on the car and passenger decks.

On the other hand, as shown in Figure $8 \mathrm{a}$, since the bottom part is under compression in a hogging condition, local deformation of the elements takes place. In addition, Figure $8 \mathrm{~b}$ shows the sagging condition in which local deformation of the elements occurs under tension.

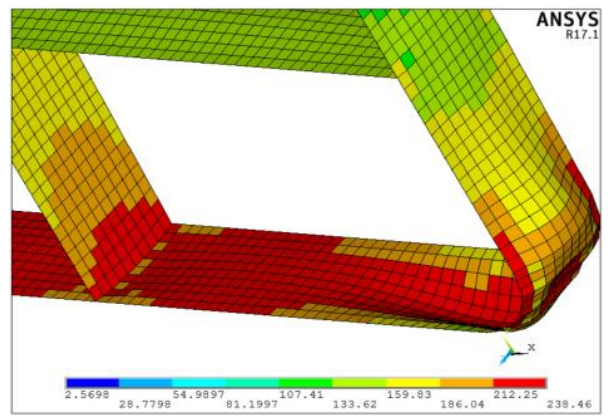

(a)

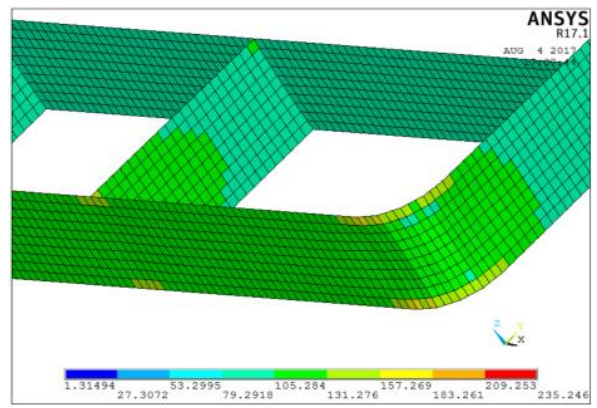

(b)

Figure 8 Local deformations in the bottom part: (a) hogging and (b) sagging

The von Mises stress distributions for hogging and sagging conditions are illustrated in Figure 9. It is clear that stress appears when the cross section is under tension or compression in the top deck and bottom part. The maximum value of the stress distribution is indicated by the MX symbol, and the neutral axis located near the car deck bythe MN symbol.

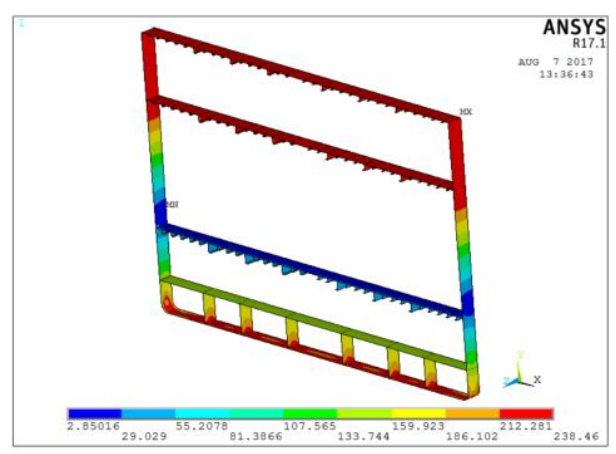

(a)

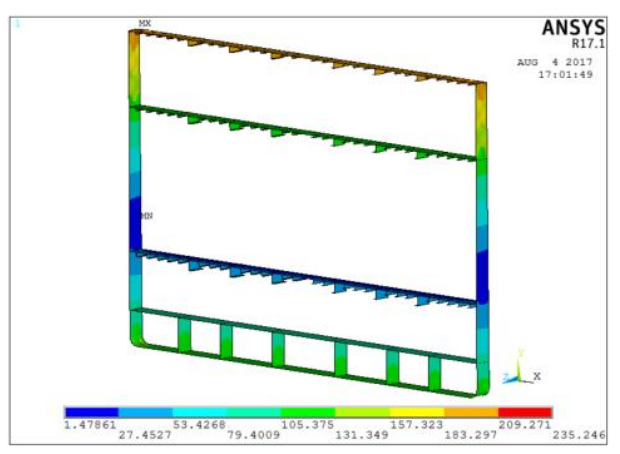

(b)

Figure 9 von Mises Stress distributions: (a) hogging and; (b) sagging 


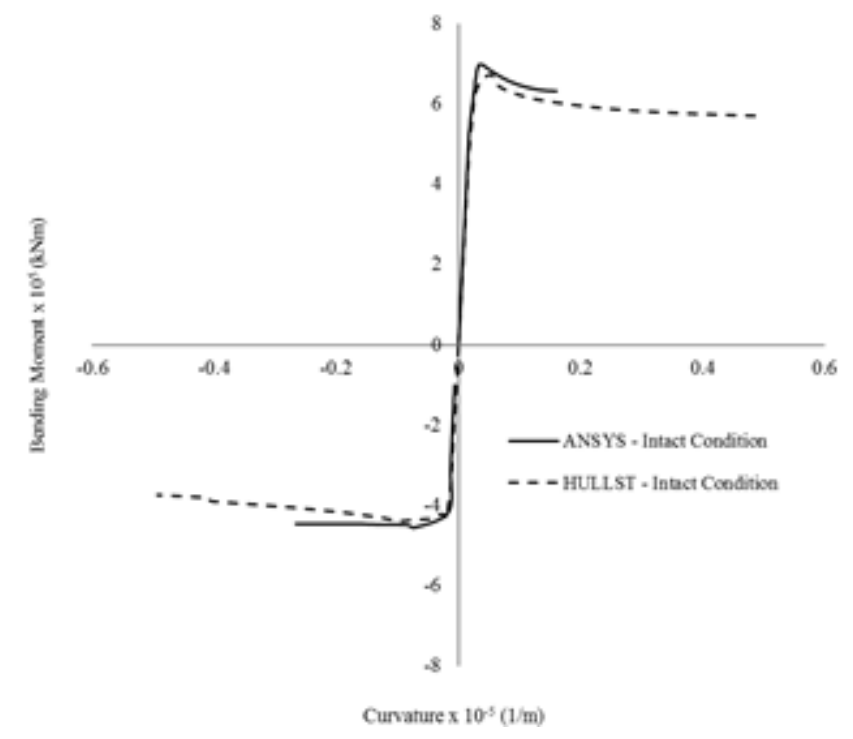

Figure 10 Comparison of the moment-curvature relationship

Furthermore, the hull girder cross section modulus is very sensitive, particulary in relation to the ultimate strength and behavior of the individual elements. The local deformation of the individual element on the cross section contributes to the its local stress, and this clearly spread to deformation and stress in the global structure, as shown in Figures 5-8, especially Figures 5 and 8 caused by buckling and yielding. In this regard, these elements are in hogging and/or sagging conditions when the bottom or deck part is under tension or compression. It is also confirmed that the section modulus represents the bending strength of the hull girder in the global ship structure. Plates and stiffened plates may suffer buckling, plastic buckling, post buckling and/or yielding in the process of achieving the ultimate strength of the ship's hull. Therefore, the ultimate strength and behavior, such as deformation of local elements, must be calculated and checked to the global structure.

Accordingly, it is necessary to confirm the ultimate strength calculated theoretically and by numerical analysis. Figure 10 shows a comparison of the moment-curvature relationship for intact under hogging and sagging conditions obtained by numerical analysis and the theoretical approach using the in-house program. The solid line is the ultimate strength obtained by numerical analysis, while the dotted line represents the that obtained by the in-house program. The deviations in ultimate strength between the FE analysis and in-house program in hogging and sagging conditions are 0.26 and 0.15 , respectively. It was found that the ultimate strength obtained by numerical analysis was in good agreement with the theoretical approach for hogging and sagging conditions. The bending stiffness both two approaches is identical in the elastic area.

\section{CONCLUSION}

Analysis of the local elements and the ultimate strength of the Ro-Ro ship, including their progressive collapse, has been made using Smith's method implemented into an in-house program, and the results compared to the numerical solution for comparison purposes. The investigation of the local elements is considered for intact in hogging and sagging conditions. In summary, the conclusion is that the deformation of the local elements on the deck and bottom parts indicate that stress concentration appears in that region. The comparison of the momentcurvature relationship for the cross section of the Ro-Ro ship is identical to the numerical solution obtained by nonlinear finite element analysis. The deformation is not significant on the passenger or car decks, because a Ro-Ro ship has several decks on the cross section. 


\section{REFERENCES}

Campanile, A., Piscopo, A., Scamardella, A., 2017. Incident of Load Combination Methods on Time-variant Oil Tanker Reliability in Intact Conditions. Ocean Engineering, Volume 130, pp. 371-384

Chen, N.Z., 2016. Hull Girder Reliability Assessment for FPSOs. Engineering Structures, Volume 114, pp. 135-147

Garbatov, Y., Saad-Eideen, S., Soares, C.G., 2015. Hull Girder Ultimate Strength Assessment based on Experimental Results and the Dimensional Theory. Engineering Structures, Volume 100, pp. 742-750

Gaspar, B., Teixeira, A.P., Soares, C.G., 2016. Effect of the Nonlinear Vertical Wave-induced Bending Moments on the Ship Hull Girder Reliability. Ocean Engineering, Volume 119, pp. 193-207

Kim, D.H., Paik, J.K., 2017. Ultimate Limit State-based Multi-objective Optimum Design Technology for Hull Structural Scantlings of Merchant Cargo Ships. Ocean Engineering, Volume 129, pp. 318-334

Kitarovic, S., Zanic, V., 2014. Approximate Approach to Progressive Collapse Analysis of the Monotonous Thin-walled Structures in Vertical Bending. Marine Structures, Volume 39, pp. 255-286

Kukkanen, T., Matusiak, J., 2014. Nonlinear Hull Girder Loads of RoPax Ship. Ocean Engineering, Volume 75, pp. 1-14

Muis Alie, M.Z., 2014. Finite Element Analysis on the Ship Hull Girder under Longitudinal Bending with Bottom Damage. In: Proceedings of the Third International Conference on Ship and Offshore Technology (ICSOT), pp.1-4

Muis Alie, M.Z., Sitepu, G., Juswan., Wahyuddin., Nugraha, A.M., Alamsyah., 2016. Finite Element Analysis on the Hull Girder Ultimate Strength of Asymmetrically Damaged Ships. In: Proceedings of the $35^{\text {th }}$ International Conference on Ocean, Offshore and Arctic Engineering (OMAE), Volume 3

Muis Alie, M.Z., 2016. The Effect of Symmetrical and Asymmetrical Configuration Shapes on Buckling and Fatigue Strength Analysis of Fixed Offshore Platforms. International Journal of Technology, Volume 7(6), pp. 1107-1116

Muis Alie, M.Z., Sitepu, G., Latumahina, S.I., 2017. The Assessment of the Hull Girder Strength of a RO-RO Ship after Damages. In: Proceeding of the $27^{\text {th }}$ International Offshore and Polar Engineering Conference (ISOPE), Volume 4, pp. 913-919

Muis Alie, M.Z., 2018. Simplified Approach on the Ultimate Hull Girder Strength of Asymmetrically Damaged Ships. International Journal of Offshore and Polar Engineering, Volume 28(2), pp. 200-205

Nugroho, F.A, Siregar, B, Putra, G.L, Dhelika, R., 2018. Study on the Alteration of Geometrical Dimensions of Tee Stiffeners Concerning the Ultimate Strength Characteristics under a Vertical Bending Load. International Journal of Technology, Volume 9(5), pp. 1027-1038

Park, D.K., Kim, D.K., Seo, J.K., Kim, B.J., Ha, Y.C., Paik, J.K., 2015. Operability of Non-ice Class Aged Ships in the Arctic Ocean - Part I: Ultimate Limit State Approach. Ocean Engineering, Volume 102, pp. 197-205

Tayyar, G.T., Nam, J.M., Choung, J., 2014. Prediction of Hull Girder Moment-carrying Capacity using Kinematic Displacement Theory. Marine Structures, Volume 39, pp. 157173

Tekgoz, M., Garbatov, Y., Soares, C.G., 2018. Strength Assessment of an Intact and Damaged Container Ship Subjected to Asymmetrical Bending Loadings. Marine Structures, Volume 58, pp. $172-198$ 
Yao, T., Sumi, Y., Takemoto, H., Kumano, A., Sueoka, H., Ohtsubo H., 1998. Analysis of the Accident of the MV Nakhodka - Part 2: Estimation of Structural Strength. Journal of Marine Science and Technology, Volume (3), pp. 181-193 